\title{
Laser Doppler Velocimetry-Phase Analysis Light Scattering System
}

National Cancer Institute

\section{Source}

National Cancer Institute. Laser Doppler Velocimetry-Phase Analysis Light Scattering

System. NCI Thesaurus. Code C78812.

An instrument that can perform laser Doppler velocimetry and phase analysis light scattering to determine the zeta potential of a sample. 